\title{
El enunciado de Súmula 602 del Tribunal Superior de Justicia de Brasil, del 22 de febrero de 2018, y la afrenta al acto cooperativo
}

The statement of the Súmula 602 from Superior Court of Justice of Brazil and the confront to the cooperative act

O enunciado de Súmula 602 do Superior Tribunal de Justiça do Brasil e a afronta ao ato cooperativo

\section{Marianna Ferraz- Teixeira* Marília Ferraz-Teixeira**}

Recibido: 16 de julio de 2018 Aceptado: 29 de noviembre de 2018

Publicado: 5 de abril de 2019

Cómo citar este artículo: Ferraz-Teixeira, M. (2019). El enunciado de Súmula 602 del Tribunal Superior de Justicia de Brasil y la afrenta al acto cooperativo. Cooperativismo \& Desarrollo, 27(1), 1-18. DOI: https://doi.org/10.16925/2382-4220.2019.01.01

Artículo de investigación. https://doi.org/10.16925/2382-4220.2019.01.01

* Universidad de Sao Paulo. Sao Paulo. Brasil.

Correo electrónico: marianna.tfadvogados@uol.com.br

** Universidad de Sao Paulo. Sao Paulo. Brasil. 


\section{Resumen}

La presente investigación busca analizar el enunciado de Súmula núm. 602 del Tribunal Superior de Justicia de Brasil, aprobado el 26 de febrero de 2018, donde se sostiene que el Código de Defensa del Consumidor es aplicable a los emprendimientos inmobiliarios promovidos por una sociedad cooperativa. Como ese texto resulta aplicable a los casos similares que estén bajo la jurisdicción de dicho tribunal y debe servir de base de juicio para los tribunales inferiores, es necesario advertir que la decisión contraviene el derecho cooperativo y omite las características peculiares entre las cooperativas de vivienda y sus socios, calificando forzadamente esta relación como de consumo. De ahí que sea necesario indagar en la especificidad que tiene el derecho cooperativo para distinguir la especial relación que se da entre las cooperativas y sus socios; así evidenciar el equívoco y el perjuicio que referida decisión jurisprudencial tendrá a futuro para las sociedades cooperativas de vivienda. Resulta igualmente necesario revisar las reglas del proceso civil y del Reglamento Interno del Tribunal Superior de Justicia para verificar la posibilidad de alterar esta negativa jurisprudencia sentada respecto de las cooperativas de vivienda.

Palabras clave: cooperativas de vivienda, derecho cooperativo, derecho del consumidor, jurisprudencia vinculante, precedente, proceso civil.

\section{Summary}

The present investigation seeks to analyze the statement of Súmula núm. 602 of the Superior Court of Justice of Brazil, approved on February 26, 2018, where it is maintained that the Consumer Defense Code is applicable to real estate ventures promoted by a cooperative society. Since this text is applicable to similar cases that are under the jurisdiction of said court and should serve as the basis of judgment for the lower courts, it is necessary to note that the decision contravenes cooperative law and omits the peculiar characteristics between housing cooperatives and its partners, forcibly qualifying this relationship as consumption. Hence, it is necessary to inquire into the specificity of cooperative law to distinguish the special relationship that exists between cooperatives and their partners; thus, evidence of the misunderstanding and prejudice that the jurisprudential decision referred to will have in the future for cooperative housing societies. It is also necessary to review the rules of the civil process and the Internal Regulation of the Superior Court of Justice to verify the possibility of altering this negative case-law sitting with respect to housing cooperatives.

Keywords: housing cooperatives, cooperative law, consumer law, binding jurisprudence, precedent, civil process

\section{Resumo}

O presente estudo busca analisar o enunciado de Súmula n. ${ }^{\circ} 602$ do Superior Tribunal de Justiça do Brasil, aprovado em 26 de fevereiro de 2018, que dispõe que o Código de Defesa do Consumidor é aplicável aos empreendimentos imobiliários promovidos por uma sociedade cooperativa. Como esse enunciado se aplica aos casos semelhantes que estejam sob a jurisdição do referido tribunal e deve servir como base para os julgamentos dos tribunais inferiores, é necessário ressaltar que a decisão se contrapõe ao Direito Cooperativo e não observa as características peculiares da relação entre as coo perativas habitacionais e seus sócios, qualificando-a forçadamente como de consumo. Por essa razão, é necessário ressaltar a especificidade que há no Direito Cooperativo para distinguir essa relação especial existente entre as cooperativas e seus associados e, assim, evidenciar o equívoco e o prejuízo que referida decisão jurisprudencial trará para o futuro das sociedades cooperativas habitacionais. É igualmente necessário rever as regras de Processo Civil e do Regimento Interno do Superior Tribunal de Justiça para verificar a possibilidade de alterar esta jurisprudência negativa para as cooperativas habitacionais."

Palavras-chave: cooperativas habitacionais, direito cooperativo, direito doconsumidor,jurisprudênciavinculante, precedente, processo civil. 


\section{Introducción}

Como consumación del desconocimiento y la desobediencia de las normas legales y de los estatutos sociales de las cooperativas de vivienda, el 26 de febrero de 2018 fue aprobado por el Tribunal Superior de Justicia de Brasil el enunciado de Súmula núm. 602 (STJ), el cual determina que el Código de Defensa del Consumidor (CDC) resulta aplicable a los emprendimientos inmobiliarios promovidos por la sociedad cooperativa.

La importancia de esta decisión radica en que, dentro del ordenamiento brasileño, una Súmula es un texto breve que demuestra la posición de los jueces en el juzgamiento de un determinado tema, creado para condensar la jurisprudencia de un tribunal (STJ, 2018). De esa manera, de acuerdo con las reglas procesales, debe ser observada por los jueces al decidir un caso concreto'. Se trata, por tanto, de una directriz sobre un tema determinado que, con carácter genérico y contenido doctrinal, funciona como una suerte de precedente a partir del caso concreto que le sirvió de base.

El problema que suscita el enunciado de Súmula núm. 602 es que las cooperativas de vivienda no reúnen los requisitos necesarios para que la actividad que desarrollan sea caracterizada como de consumo. Bien sea porque que sus socios no encuadran en la definición de consumidor, o porque la cooperativa no satisface el concepto de proveedor ni ejerce una actividad lucrativa en el mercado.

En realidad, ellas son sociedades sui generis y su objetivo principal es suministrar viviendas exclusivamente a sus socios. De ahí que todo el aporte financiero hecho por estos últimos revierta hacia ellos mismos, pues después de costear la construcción de una vivienda de forma menos onerosa, el valor de las cuotas de participación es utilizado para la suscripción de la escritura de adjudicación del inmueble. Esto determina que no exista ánimo de lucro, sino la coordinación de la ayuda mutua para lograr un objetivo común.

Por ende, su actividad se basa en aquello que el derecho latinoamericano ha llamado el "acto cooperativo", el cual no importa una actividad de mercado, dado que su celebración entre la cooperativa y sus socios - o entre cooperativas de entre sí- se realiza para la consecución del objeto social. Al fin y al cabo, esta relación expresa la finalidad mutualista que es la esencia de esa clase de sociedad y debe regirse por el derecho cooperativo, que asegura una regulación propia acorde con su naturaleza diferenciada (ACl Américas, 2009).

Por el contrario, las sociedades inmobiliarias buscan exclusivamente el lucro del propietario - que agrega valor al costo de la construcción-, mientras que la relación

\footnotetext{
1 Véase los artículos 926 y 927 del Código Procesal Civil brasileño, que se reproducen más adelante (notas 3 y 4$)$.
} 
con los compradores de cada unidad inmobiliaria se agota en la celebración de un contrato cuyo modelo es uniforme, impreso y estandarizado y donde el consumidor acepta el contenido, sin posibilidad de negociación, con la consiguiente asimetría de fuerzas.

Debido al desconocimiento de la manera de actuación de una cooperativa de vivienda, y ante la confusión generada por la similitud con un emprendimiento común, el enunciado de Súmula se equivoca al minusvalorar la autonomía del derecho cooperativo y la necesidad de sujeción a su disciplina específica. Asimismo, por tener una aplicación determinada en la ley procesal, este pronunciamiento traerá diversos problemas a futuro para este tipo de cooperativas.

El presente artículo busca analizar las características legales y doctrinales del cooperativismo, especialmente el cooperativismo de vivienda, con el objetivo de distinguir la relación existente entre cooperativa y sus socios de las demás relaciones caracterizadas como de consumo, para así demostrar el error cometido por la el Tribunal Superior de Justicia de Brasil con el enunciado de Súmula núm. 602. Para finalizar, se ofrece un pequeño cuerpo de conclusiones.

De esta manera, será posible identificar si ese ramo del cooperativismo brasileño sigue siendo una opción viable respecto de las demás iniciativas existentes para adquisición de un inmueble y cuáles son los efectos jurídicos de una decisión de esa relevancia para el futuro de esta clase de sociedades.

\section{La contextualización de las cooperativas de vivienda en Brasil}

El cooperativismo puede ser entendido de dos maneras: por una parte, designa un sistema de organización económica que busca eliminar los desajustes sociales provenientes del capitalismo. Por otra, representa la doctrina compuesta por un conjunto de principios que rigen el comportamiento de los humanos integrados a ese sistema (Franke, 1973, p.1).

Según Luis Amaral, el cooperativismo es obra del corazón y surge cuando las grandes figuras de la economía política fracasaron o vieron reducidos los frutos de su inteligencia, de su talento y de su cultura al mínimo. Tiene como base una alianza de esfuerzos para el aumento de la eficiencia productiva, la reducción de gastos, el perfeccionamiento de la producción y el mejor aprovechamiento del trabajo, sin dejar de lado la propagación del interés propio mediante el cuidado del interés de los demás (Amaral, 1938, pp.22-25 y 38).

De ese modo, el cooperativismo valora al individuo por la solidaridad social y puede ser resumido con la siguiente máxima: "Uno por todos, todos por uno". La 
razón es que los personas dejan de trabajar solo para sus necesidades, dividiendo, además de los anhelos de un grupo, las necesidades que tienen en común, y ofrecen su participación para satisfacerlas (Miranda, 2017, p.33).

El déficit habitacional es un problema antiguo en Brasil y actualmente se cuantifica en la falta de 7.757 .000 de viviendas, cuyo origen proviene en gran parte del comprometimiento de la renta familiar en el pago de alquiler y de la cohabitación (Villas Boas; Conceição, 2018). Según datos de la ONU, 33 millones de brasileños no tienen dónde vivir, y lo hacen en lugares inapropiados (Augusto, 2018). En consecuencia, es acuciante buscar alguna manera de reducir este déficit habitacional de forma efectiva, función que ha sido cumplida por las cooperativas de vivienda (cooperativas habitacionais).

El cooperativismo habitacional, más conocido en los países de lengua castellana como de vivienda, nació en Brasil como una de las formas prioritarias de aplicación de los recursos provenientes del Sistema Financiero da Habitación. Creado en 1964, este sistema tenía por objetivo la construcción, el mantenimiento y la administración de viviendas o conjuntos habitacionales para sus socios, proporcionándoles una serie de servicios relacionados, como la adquisición de viviendas y de terrenos para construcción, la propia construcción, el diseño y construcción de inmuebles (Niscolo; Picanço, 2007, p.306 y Menezes, 2005, p. 126).

Bajo este régimen, la cooperativa de vivienda es una sociedad civil sin fines de lucro, compuesta por un determinado número de personas cuyo objetivo común es la adquisición de una vivienda. Los socios que las integran poseen los mismos derechos y obligaciones, y todas las decisiones deben ser tomadas de común acuerdo en las asambleas, según las disposiciones de la Ley 5764, de 16 de diciembre de 1971 (Pinho; Abramides; Araujo, 1984, p. 323). De este modo, ellas se diferencian de las demás sociedades por proveer de viviendas a sus socios y no por tener el objetivo de construir para colocar esas unidades en el mercado y así obtener un lucro repartible (Gutiérrez, et al., 2011, p. 260). En la actualidad existen 284 cooperativas de vivienda activas en Brasil.

Con la promulgación de la Constitución Federal de 1988 y las modificaciones del Sistema Financiero de Habitación a lo largo de los años, las cooperativas habitacionales pasaron a producir viviendas por autogestión, es decir, a través de financiamiento propio, reduciendo el costo de adquisición. Esto ha traído consigo que la obra sea más barata, logrando mejores condiciones y plazos de pago para los socios, además de una construcción de calidad. Sin embargo, ese tipo cooperativo ha encontrado la negación de sus características legales por parte del poder judicial y el desconocimiento de la sociedad en relación con su verdadero propósito, que es la promoción de viviendas bajo la ayuda mutua (Niscolo; Picanço, 2007, pp.310-311 y OCB, 2016). 


\title{
El acto cooperativo en las cooperativas de vivienda y su distinción con el acto de consumo
}

La cooperativa emerge de la voluntad y de la necesidad de un grupo de personas para la búsqueda de soluciones donde prevalece el interés del asociado. Por esa razón, de acuerdo con Ariel Guarco:

\begin{abstract}
Las operaciones realizadas entre los asociados de una cooperativa y ésta son actos intra sociales, que se diferencian de las relaciones entre [los] comerciante y sus clientes. Las primeras responden a la idea de servicio que la comunidad cooperativa presta a sus socios para eliminar una intermediación onerosa y procurarles un ahorro que se traducirá en el "retorno", por lo que la relación comprende ingredientes del mandato y de la gestión asociativa [y] que la distancia[n] de la compraventa y excluye decididamente el acto de comercio. (Guarco, 2013, p. 200).
\end{abstract}

Según Pastorino, el acto cooperativo es la expresión jurídica de la solidaridad, de la autoayuda y de la ayuda mutua, difiere del negocio jurídico ordinario que se caracteriza por la existencia de intereses contrapuestas entre las partes. Además, son los socios quienes dirigen el acto cooperativo hacia ellos mismos y, por esa razón, no existe agresión a la esfera jurídica ajena, ni la posibilidad de una voluntad de avasallar, ni que un tercero quede sometido a una declaración de voluntad en la que no tuvo participación. En suma, no cabe la arbitrariedad (Pastorino, 1993, p. 34 y 40).

Se trata de un acto en que convergen los intereses generales e individuales de los socios, además de no prever cláusulas leoninas en virtud de la equidad esencial existente entre ellos (Pastorino, 1993, p. 42).

Así la naturaleza del vínculo es asociativa y está establecida por la ley que rige el cooperativismo, siendo aplicable a todas las ramas cooperativas. Esta asociación es la principal razón para explicar y justificar la calidad de socio de todos aquellos en que converja una triple condición:

a) Los socios son los dueños de la cooperativa, pues aportaron el capital necesario para la constitución de la sociedad.

b) Los socios son los gestores de la sociedad, gobiernan, administran y controlan la cooperativa de acuerdo con sus propias reglas de gobernanza.

c) Los socios son los beneficiarios de los servicios que proporciona la cooperativa, sin que sea necesario depender de terceros (Cracogna, 2017, pp.12-13). 
El profesor Dante Cracogna explica de la siguiente forma el hecho de que no exista contraposición de intereses entre la cooperativa y sus socios:

Cuando la cooperativa presta el servicio a sus asociados realiza un acto cooperativo, y no un contrato de compraventa de mercadería o de locación de servicios de seguro o de mutuo, según sea la clase de cooperativa en cuestión. En todo caso, se trata de actos tendientes a la obtención del servicio de la cooperativa por parte de los asociados, con lo cual la figura contractual respectiva queda subsumida en el acto cooperativo y los caracteres de aquélla sólo subsidiariamente resultan aplicables. Cabe recordar que en el acto de comercio, a diferencia de lo que sucede en el acto cooperativo, el propósito de lucro es esencial. El comerciante cumple mejor su objetivo cuanto más lucro es capaz de obtener; por lo tanto, adquirir una mercadería o servicio al más bajo precio posible y enajenarla al precio más elevado a fin de lograr el mayor lucro constituye el desiderátum del acto de comercio. No puede ser, pues, más evidente la contraposición de intereses entre el proveedor y el consumidor o usuario toda vez que éste tratará siempre de obtener la mercadería o el servicio al menor precio posible. (Cracogna, 2013, p. 7).

De esa manera, el acto cooperativo en una cooperativa de vivienda es aquel celebrado entre ésta y cada uno de sus socios con la finalidad de que éstos obtengan, a través de los servicios prestados por la cooperativa, el derecho a la vivienda propia, sin intermediación y por un precio justo. Además, las unidades habitacionales producidas por ellas no están disponibles a favor de quienes no forman parte de la cooperativa.

Esta relación no puede ser considerada como una compraventa, un contrato de locación de obra, o un mandato otorgado a la entidad cuyo objetivo es conseguir la vivienda para los socios, pues no constituye más que un acto cooperativo. Ese carácter es suficiente para calificar jurídicamente esta relación. Por ende, el precio será siempre provisorio, la construcción se acometerá al costo calculado según la estimación previa a la obra, siendo posible que exista un incremento del valor en razón del tiempo de duración de la construcción y de los efectos inflacionarios de dicho periodo (Guarco, 2013, pp. 202-203).

Según Guarco, el costo final sólo será definido tras la finalización total de la construcción y cada aporte hecho por los asociados será contabilizado por separado como si fuera un "crédito a favor del asociado a cuenta del precio a pagar al momento de la suscripción de la escritura de adjudicación" (Guarco, 2013, p. 203). 
Por su parte, la relación de consumo ocurre entre proveedor y consumidor y tiene como objeto un producto o servicio cuya adquisición se concreta merced a un contrato de adhesión, que posee términos aprobados por la autoridad competente 0 establecidas unilateralmente por el proveedor, sin posibilidad de discusión o modificación del contenido por parte del consumidor. Ella descansa, entonces, sobre un pacto ofrecido al público en un modelo uniforme, en general impreso y estandarizado, donde sólo se completan los datos de identificación del consumidor, quien acepta íntegramente los términos redactados por la empresa, con la consiguiente asimetría de fuerzas en la negociación que impide la alteración o cambio de las cláusulas y la adecuada comunicación entre las partes (Teixeira, 2018, p. 24).

Esto refleja la vulnerabilidad de la parte que, por razones económicas o educativas, es más frágil dentro de la relación. Esto es el pilar de la protección del Código de Defensa del Consumidor, el cual busca garantizar un equilibrio en la relación para asegurar la preservación del principio de confianza. De ahí que siempre haya una interpretación de las cláusulas que sean favorable a la parte que adhiere a esta clase de contratos (Efing, 2015).

Por estas razones, no se puede afirmar que la relación existente entre una cooperativa de vivienda y sus socios sea de consumo - aquella que se da entre proveedor y consumidor, que tiene como objeto el suministro de un producto o la prestación de un servicio que genera ganancia para el primero-, pues los socios adquieren la vivienda combinando los esfuerzos individuales de cada uno ellos, sin que nadie busque un beneficio económico personal con dicha actividad.

\section{El enunciado de Súmula núm. 602 del Tribunal Superior de Justicia de Brasil}

El 26 de febrero de 2018, el Tribunal Superior de Justicia de Brasil aprobó el enunciado de Súmula núm 602, el cual sostiene que el Código de Defensa del Consumir es aplicable a los emprendimientos inmobiliarios promovidos por la sociedad cooperativa².

2 El Tribunal Superior de Justicia es el responsable de uniformizar la interpretación de la ley federal en todo el territorio nacional, resolviendo de manera definitiva las contiendas civiles y criminales que no involucren una materia constitucional o que sean de competencia de la justicia especializada (artículo 105 de la Constitución brasileña). 
De acuerdo con los artículos $926^{3}$ y $927^{4}$ del Código Procesal Civil, un enunciado de súmula representa la consolidación de las decisiones mayoritarias de un tribunal, de modo que ese resumen sea aplicable a casos similares que estén bajo su jurisdicción, y también sirve de base para las decisiones de los tribunales de instancias inferiores.

El Reglamento Interno del Tribunal Superior de Justicia señala que se podrán inscribir en una súmula los enunciados correspondientes a las decisiones adoptadas en un caso por la unanimidad de los miembros que componen la Corte Especial o la Sección, o bien cuando ellas hayan sido dadas por mayoría absoluta en al menos dos juicios concordantes (artículo 122, § 1), debiendo dicha súmula ser publicada tres veces en el Diario de la Unión (artículo 125) (STJ, 2018, pp. 82-83).

En el caso que se analiza, la decisión jurisprudencial que resultó en la publicación del enunciado de Súmula núm. 602 proviene del desconocimiento de la naturaleza jurídica peculiar que tienen las sociedades cooperativas por parte de los tribunales de justicia, que las equipara a las sociedades de giro inmobiliario, sin respetar el estatuto social y el principio de libre adhesión de los socios. Cumple preguntarse, entonces,

3 El artículo del Código Procesal Civil dispone: Os tribunais devem uniformizar sua jurisprudência e mantê-la estável, íntegra e coerente.

$\S 1^{\circ} \mathrm{Na}$ forma estabelecida e segundo os pressupostos fixados no regimento interno, os tribunais editarão enunciados de súmula correspondentes a sua jurisprudência dominante.

$\S 2^{\circ}$ Ao editar enunciados de súmula, os tribunais devem ater-se às circunstâncias fáticas precedentes que motivaram sua criação. (Ley 13.105 de 2015)

4 El artículo 927 del Código Procesal Civil señala: Os juízes e os tribunais observarão:

I - as decisões do Supremo Tribunal Federal em controle concentrado de constitucionalidade;

II - os enunciados de súmula vinculante;

III - os acórdãos em incidente de assunção de competência ou de resolução de demandas repetitivas e em julgamento de recursos extraordinário e especial repetitivos;

IV - os enunciados das súmulas do Supremo Tribunal Federal em matéria constitucional e do Superior Tribunal de Justiça em matéria infraconstitucional;

V - a orientação do plenário ou do órgão especial aos quais estiverem vinculados.

$\S 1$ 1ㅇs juízes e os tribunais observarão o disposto no art. 10 e no art. 489 , § 1o, quando decidirem com fundamento neste artigo.

$\S 2^{\circ} \mathrm{A}$ alteração de tese jurídica adotada em enunciado de súmula ou em julgamento de casos repetitivos poderá ser precedida de audiências públicas e da participação de pessoas, órgãos ou entidades que possam contribuir para a rediscussão da tese.

$\S 3$ o Na hipótese de alteração de jurisprudência dominante do Supremo Tribunal Federal e dos tribunais superiores ou daquela oriunda de julgamento de casos repetitivos, pode haver modulação dos efeitos da alteração no interesse social e no da segurança jurídica.

$\S 4^{\circ} \mathrm{A}$ modificação de enunciado de súmula, de jurisprudência pacificada ou de tese adotada em julgamento de casos repetitivos observará a necessidade de fundamentação adequada e específica, considerando os princípios da segurança jurídica, da proteção da confiança e da isonomia.

$\S 5 \circ$ Os tribunais darão publicidade a seus precedentes, organizando-os por questão jurídica decidida e divulgando-os, preferencialmente, na rede mundial de computadores. (Ley 13.105 de 2015) 
cuán obligatorio resulta este pronunciamiento hacia el futuro. Estos aspectos se tratarán en los siguientes apartados.

\section{¿Es siempre obligatoria la aplicación de un enunciado de súmula?}

Dada la tradición romana del ordenamiento jurídico brasileño, las normas emanadas del poder legislativo son la base del derecho nacional, y desplazan a un lugar secundario a otras fuentes del derecho. Esto explica que la ley de introducción a las normas del derecho brasileño disponga que la ley es la principal fuente del derecho nacional y que las demás -analogía, costumbres y principios generales del derecho- sólo serán aplicables en caso de falta de aquélla (Teixeira, 2016, pp. 51-52).

Hasta la promulgación del nuevo Código Procesal Civil en 2015, había discusión sobre la inclusión de la jurisprudencia como fuente formal de derecho, donde comparecen los enunciados de súmula como sistematización de las decisiones reiteradas de los tribunales superiores. Los autores que se decantaban por la opinión negativa sobre este punto sostenían que dichos enunciados no eran obligatorios, debido al principio de libre convencimiento del juez, que es siervo de las leyes y cuyas decisiones sólo resultan aplicables respecto de las partes litigantes. Quienes se inclinaban por dar valor a esos enunciados argumentaban que la jurisprudencia innova en cuestiones jurídicas al establecer criterios que no son estrictamente legales, pues en una decisión se reúnen diversos elementos que, en última instancia, son declarados como derecho por el poder judicial (Teixeira, 2016, p. 52).

Sin embargo, ocurre que la nueva redacción del Código de Proceso Civil prevé que las cortes pueden fijar su jurisprudencia uniforme por medio de enunciados sumulares que serán observados por sus jueces y por otros tribunales. En el caso de los enunciados de súmulas del Tribunal Superior de Justicia, esto sucede cuando se trata de asuntos infra constitucionales. Gracias a este reconocimiento, los enunciados de súmula pasaron a tener un carácter vinculante y, por tanto, su aplicación se volvió obligatoria para los tribunales.

Es cierto que un criterio de decisión ya adoptado puede cambiar y, cuando ello acaece, es necesario hacer una revisión de la jurisprudencia sintetizada en súmula, según el procedimiento previsto por la ley procesal. El Reglamento Interno del Tribunal Superior de Justicia dice que cualquiera de los ministros de ese tribunal puede proponer una revisión de la súmula a la Turma de la que forma parte. Si se acoge la propuesta, se dirige a la Corte Especial o a la Sección, que alterará o cancelará la decisión previa por mayoría absoluta de sus miembros, siempre que se cuente con la presencia 
de al menos dos tercio de sus integrantes (artículo 125) (STJ, 2018, p.83). Esto significa que esa revisión sólo ocurre cuando hay un cambio significativo en la composición del tribunal, lo que puede tardar años en producirse si se considera que el Tribunal Superior de Justicia está compuesto por 33 ministros que se cesan en su cargo a los setenta años de edad (artículo 74 de la Ley Organica de la Magistratura Nacional). De ahí proviene el gran problema de la aprobación reciente del enunciado de Súmula núm. 602 por parte del Tribunal Superior de Justicia, que determina la aplicación de una normativa - como es el derecho del consumo- que no se corresponde con las características especiales del cooperativismo.

\section{La distorsión que produce la aplicación del enunciado de Súmula núm. 602 a las cooperativas de vivienda}

La relación de consumo típica está constituida por dos sujetos: el consumidor y el proveedor. De acuerdo con el Código de Defensa del Consumidor, los consumidores son aquellas personas físicas o jurídicas que, por definición legal, adquieren o utilizan productos o servicios como destinatarios finales (artículo 2), mientras tienen la calidad de aquellas personas físicas o jurídicas, de naturaleza pública o privada, nacional o extranjera, así como entes despersonalizados, que desarrollen actividades de producción, montaje, creación, construcción, transformación, importación, exportación, distribución o comercialización de bienes o servicios (artículo 3) (Ley 8078 de 1990).

El referido código busca proteger la vulnerabilidad del consumidor ante el proveedor debido a la relación desequilibrada que resulta del mayor conocimiento técnico, económico o científico que posee este último. Dicha protección es reconocida como un derecho fundamental por su importancia económica y, por eso, los tribunales brasileños protegen, con gran esfuerzo, las relaciones que sean desfavorables a los consumidores.

Sin embargo, no cualquiera actividad del proveedor estará sujeta a la disciplina de protección del consumidor, pues es necesario que ella sea ofrecida en el mercado. Este componente indispensable para la caracterización de la relación supone la concurrencia de dos elementos: la remuneración y la búsqueda de un lucro (Grinover, 2013, pp. 39-40).

Como enseña Ronaldo Gaudio, la jurisprudencia de las cortes superiores de Brasil ha mostrado un desprecio a la interacción económica estructural que se da entre el emprendimiento cooperativo y sus socios, la que no da cuenta de una relación de consumo, sino de una especie de relación obligatoria específica llamada "acto cooperativo" (Gaudio, 2017, p.89). Según este autor, detrás de esta tendencia 
existe una negativa por parte del poder judicial de reconocer el régimen peculiar del acto cooperativo, pese a que éste está establecido en una legislación especial que es distinta y anterior al Código de Defensa del Consumidor (Gaudio, 2017, p.89).

Es importante señalar que dicho código no se hace cargo de las características específicas del cooperativismo, que permite a sus socios concretar la solidaridad en el desarrollo de una actividad económica gracias a los principios de doble calidad y de retribución personal diferenciada (Teixeira, 2018, p. 32). El primero de ellos comporta que el socio ejerce una doble función en la cooperativa de la que forma parte, puesto que es al mismo tiempo miembro y usuario. El segundo principio implica que el socio recibe una retribución personal por su actividad autónoma, esta es superior a la que obtendría si no estuviese asociado a la cooperativa.

De esto se sigue que el análisis de cualquier cuestión legal que involucre a las cooperativas debe tener en cuenta sus características propias y las relaciones sui generis a las que ellas dan lugar (Meira, 2009, p.25). Por eso, la ley marco para las cooperativas de América Latina, elaborada por el capítulo regional de la Alianza Cooperativa Internacional como la Resolución núm. 193 de la Organización Internacional del Trabajo, enfatiza la importancia de la observancia y aplicación de disciplina cooperativa, permitiendo la aplicación de normas de derecho civil solamente cuando sean compatibles con su naturaleza distinta y siempre de manera subsidiaria 5 .

Para Dante Cracogna, aproximar la situación de los socios de la cooperativa a la de los consumidores emana de la ignorancia sobre la naturaleza jurídica de las cooperativas o, aun peor, entraña una forma de provocar inconvenientes a las cooperativas bajo el pretexto de igualdad de trato con otras formas empresariales, resultando ello en un desincentivo a su actuación con un evidente sacrificio al principio de organización libre y voluntaria de sus miembros (Cracogna, 2013, p.13).

Nótese que hay decisiones judiciales favorables a las cooperativas de vivienda, como ocurre con la sentencia dictada por el Tribunal de Justicia del Distrito Federal y de los Territorios en la Apelación Civil núm. 2016.01.1.060385-6. En esta sentencia se resolvió que las cooperativas de vivienda están constituidas para suministrar

5 En este sentido, el profesor Dante Cracogna explica: "La cooperativa no tiene el carácter de un proveedor de bienes o servicios enfrentado con el asociado para lucrar a sus expensas, como sucede en la actividad comercial corriente. En la cooperativa, los asociados se reúnen para adquirir en común bienes o procurarse servicios que van utilizando a medida que los que necesitan; la cooperativa actúa como una despensa o almacén común de los asociados del cual se van abastecimiento conforme con sus particulares requerimientos. Lejos se encuentra esta situación, pues, de la de un proveedor común que compra para revender a los consumidores lucrando con la diferencia entre el costo y el precio de venta. Si en la cooperativa llegara a existir una diferencia entre el costo y el precio que los asociados abonan por los bienes, entonces se les reembolsará dicha diferencia por vía del retorno proporcional a las adquisiciones realizadas por cada uno" (Cracogna, 2013, p.12). 
exclusivamente a sus socios la construcción y adquisición de inmuebles a un costo menor que el del mercado a través de la administración de las cuotas suscritas. Las cooperativas de vivienda comportan, entonces, una sociedad civil peculiar - sin fines de lucro-, que ha sido creada para prestar servicio específico a sus socios, gracias a la comunión de esfuerzos y la suscripción de cuotas de participación. Incluso más, el propio Tribunal Superior de Justicia, en el fallo del Recurso Especial núm. 1.535.888/ $M G$, reconoció la inaplicabilidad de la disciplina de protección del consumidor a las cooperativas, dada la autonomía y especificidad de su derecho particular.

Pero estas decisiones no tienen cómo cambiar la recién aprobada Súmula 602, la cual tiene su aplicación determinada por reglas procesales y que muestra cómo los tribunales brasileños no tienen un mayor conocimiento del derecho cooperativo y adoptan la legislación del consumidor como base de decisión en detrimento de la legislación especial, desobedeciendo los estatutos y la voluntad de los socios y, con ello, los principios de la legalidad y de pacta sunt servanda.

Esa posición también es perceptible en otras ramas del cooperativismo y en gran parte se debe a la inexistencia de la enseñanza del derecho cooperativo en los programas de estudios de las facultades de derecho. En las demás asignaturas casi no hay mención sobre la naturaleza de ese tipo societario y eso explica que pocas personas busquen especializarse en la materia. Siendo esto así, es natural que los operadores jurídicos hagan analogía de las situaciones propias de las cooperativas con aquellas de mayor ocurrencia, aplicando el derecho común.

Además, los medios de comunicación dan demasiada cobertura a las falsas cooperativas, aunque sean casos minoritarios, creando de esta manera en la conciencia popular un prejuicio respecto de la sociedad cooperativa. Por supuesto, esto sin contar con el desconocimiento de los propios socios sobre los derechos y deberes que asumen al asociarse, lo que redunda en la mala gestión del negocio y, consecuentemente, en la disolución de la cooperativa sin que ésta alcance el fin para el cual ha sido creada, dando paso a una disputa judicial para que el socio pueda recuperar la inversión realizada.

Por lo antes dicho, la cancelación de la mencionada súmula tiene pocas posibilidades de ocurrir en el corto plazo y, como resultado, seguramente habrá un desincentivo al aumento de esta rama cooperativa. La relación entre la cooperativa y sus socios, cuando se considera como un acto de consumo, puede conllevar pérdidas económicas considerables si llega a judicializarse y, con ello, o la conclusión del trabajo emprendido no se conseguirá o su costo puede subir demasiado, impidiendo la superación del déficit habitacional existente en Brasil, especialmente en relación con la población de menor renta. 


\section{Conclusiones}

El presente artículo ha pretendido ofrecer algunas consideraciones que sean útiles para explicar la equivocada decisión que ha entrañado la publicación de la jurisprudencia dominante por parte del Tribunal Superior de Justicia en lo que respecta a las relaciones de las cooperativas de vivienda con sus socios.

Con ese propósito se ha hecho una contextualización del cooperativismo de vivienda en Brasil, el cual da una respuesta adecuada y eficiente al déficit habitacional que tiene el país, para explicar enseguida la diferencia entre el acto cooperativo y las relaciones de consumo.

En una cooperativa de vivienda, el acto cooperativo es aquel que se tiene lugar entre la cooperativa y cada uno de sus socios para que éstos obtengan, a través de los servicios prestados por la cooperativa, el derecho a la vivienda propia, sin intermediación y por un precio justo. Además, se debe considerar que las unidades habitacionales no son asequibles a personas que no forman parte de la cooperativa, de suerte que la operación no puede ser considerada como una operación de mercado, como ocurre con una compraventa, porque faltan sus requisitos propios -la remuneración y la búsqueda de un lucro por parte del proveedor-.

De esto se sigue que la relación trabada entre la cooperativa de vivienda y sus socios es peculiar y su análisis se debe hacer a la luz de la legislación específica que resulte adecuada a su naturaleza. Cualquier examen de la cuestión bajo una concepción diversa -incluso desde la perspectiva del derecho del consumo- es inadecuado.

Por esa razón, un análisis sobre la formación de una súmula y su obligatoriedad es esencial para abordar el problema de la publicación de una corriente jurisprudencial que perjudica el cooperativismo, pues la reciente aprobación del enunciado de Súmula núm. 602 por parte del Tribunal Superior de Justicia uniforma la jurisprudencia mayoritaria de esa corte, que pasa a ser obligatoria para todos los jueces y tribunales en materia infra constitucional, pese al equívoco examen que efectúa respecto de la naturaleza jurídica especial de las cooperativas.

Este error conceptual tiene distintas causas, entre las que cabe mencionar: 1) la ausencia de enseñanza del derecho cooperativo en las facultades de derecho; 2) la divulgación en los medios de comunicación de los emprendimientos que se dicen cooperativas, pero en realidad jamás fueron creadas para cumplir con los objetivos de solidaridad y ayuda mutua que son propios de ellas; y 3) la mala gestión que se deriva de la falta de compromiso de los socios con los valores y principios cooperativos. 
Por lo demás, con esta interpretación el cooperativismo, las cooperativas y los socios pierden de manera general, porque sus reglamentos internos, sus decisiones organizacionales y su legislación propia son depreciados a favor de la aplicación de una disciplina que no considera las especificidades de su tipo societario.

Sin respaldo judicial, las cooperativas de viviendas, a pesar de los reglamentos y principios que sostienen su existencia, dejarán de ser una alternativa al desarrollo habitacional, y todo el esfuerzo conjunto y solidario de sus socios no será suficiente, pues las relaciones entre ambos serán tratadas como las relaciones establecidas entre las constructoras y sus clientes o consumidores. De esta forma, las personas menos favorecidas tendrán aún más dificultades para obtener una vivienda propia y el déficit habitacional que existe en el presente en Brasil tardará mucho tiempo en ser superado.

Es fundamental que las características del cooperativismo y del acto cooperativo estén bien delineadas y difundidas, para que puedan ser distinguidas de las relaciones de consumo. Sólo de esta manera, y dadas las dificultades para revisión de la súmula, será posible cambiar la jurisprudencia y posiblemente cancelar la reciente uniformización jurisprudencial. Para eso es necesario tiempo y una mayor comprensión de las particularidades del derecho cooperativo.

\section{Referencias}

ACl Américas. (2009). Ley Marco para las cooperativas de América Latina. San José, Costa Rica: Alianza Cooperativa Internacional para las Américas. Recuperado de: https://www. aciamericas.coop/IMG/pdf/LeyMarcoAL.pdf. Acceso en 13 out.2018.

Amaral, L. (1938). Tratado brasileiro de cooperativismo. São Paulo: Revista dos Tribunais.

Augusto, O. (2018). 33 milhões de brasileiros não têm onde morar, aponta levantamento da ONU. Correio Braziliense. Recuperado de: https://www.correiobraziliense.com.br/app/noticia/brasil/2018/05/03/interna-brasil,678056/deficit-de-moradias-no-brasil-chega-a-6-3-milhoessp-tem-a-maior-defa.shtml.

Cracogna, D. (2013). El acto cooperativo y la defensa del consumidor. Bahía Blanca y Argentina: GIDECOOP UNS.

Cracogna, D. (2017). ¿Asociados, usuários, clientes? Identidad Cooperativa, XVII(94). Buenos Aires: Fedecoba. 
Efing, A.C. (2015). Contratos e procedimentos bancários à luz do Código de Defesa do Consumidor. São Paulo: Editora Revista dos Tribunais.

Franke, W. (1973). Direito das Sociedades Cooperativas. São Paulo: Saraiva.

Gaudio, R. (2017). Instituições financeiras cooperativas e a defesa do consumidor - lineamentos estratégicos para contorno da equivocada jurisprudência dominante do Superior Tribunal de Justiça. Revista da Procuradoria-Geral do Banco Central, 11(1).

Grinover, A.P. (2013). Parecer jurídico sobre o Código de Defesa do Consumidor e as entidades fechadas de previdência complementar. En A. P. Grinover, et al. A inaplicabilidade do Código de Defesa do Consumidor para as entidades de previdência complementar. Cejuprev.

Guarco, A. E. (2013). El cooperativismo argentino - una esperanzadora mirada al futuro. Buenos Aires: Intercoop.

Gutiérrez, D., et al. (2011). Derecho cooperativo uruguayo. Montevideo: Fundación de Cultura Universitaria.

Internacional. (2016). Alianza Cooperativa Internacional para las Américas. Lei Marco para as cooperativas da América Latina. Recuperado de: http://aciamericas.coop.

Internacional. (2017). Organização Internacional do Trabalho. Resolução n. 193. Recuperado de: http://www.oitbrasil.org.br.

Marques, C.L. (2016). Contratos no Código de Defesa do Consumidor: o novo regime das relações contratuais. São Paulo: Editora Revista dos Tribunais.

Meira, D.A. (2009). O Regime Económico das Cooperativas no Direito Português: o capital social. Porto: Vida Económica.

Menezes, A. (2005). Nos rumos da cooperativa e do cooperativismo. Brasília: Confebrás.

Miranda, J.E.(2017).Filosofía cooperativa-análisis del proceso deconformación del cooperativismo. Curitiba: Juruá..

Niscolo, W.K. y Picanço, R.K. (2007). Cooperativismo no Sistema Financeiro de Habitação. En G. Krueger e A.B. Miranda (Coord.). Comentários à legislação das sociedades cooperativas. Belo Horizonte: Mandamentos. 
Pastorino, R.J. (1993). Teoría General del Acto Cooperativo. Buenos Aires: Intercoop Editora Cooperativa..

Pinho, D.B.; Abramides, M.B.C. y Araúo, S. (1984). Cooperativas Habitacionais. En P. Diva Benevides. Tipologia Cooperativista. São Paulo: CNPq.

Teixeira, M.F. (2016). A inaplicabilidade do Código de Defesa do Consumidor às cooperativas de crédito: uma abordagem da jurisprudência do STJ e do TJDFT à luz do princípio da igualdade e das regras de interpretação normativa. Brasília: Vincere Associados.

Teixeira, M.F. (2018). A observância das regras processuais no declínio de competência em ação de execução movida por cooperativa financeira. Revista de Doutrina e Jurisprudência, 53(109), 1.

Villas Boas, B. e Conceição, A. (2018). Déficit de moradias já chega a 7,7 milhões. Valor Econômico. Recuperado de: https://www.valor.com.br/brasil/5498629/deficit-de-moradiasno-pais-ja-chega-77-milhoes.

\section{Legislatura}

LeiComplementarn. 35, de 14 de março de 1979. Recuperado de: http//www.cnj.jus.br/publicacoes/ lei-organica-da-magistratura-nacional. Acceso en 21 nov. 2018

Lei n. 5.764, de 16 de dezembro de 1971. Recuperado de: http://www.planalto.gov.br. Acceso en 09 mar. 2017.

Lei n. 8.078, de 11 de setembro de 1990. Recuperado de: http://www.planalto.gov.br. Acceso en 09 mar. 2017.

Lei n. 13.105, de 16 de março de 2015. Recuperado de: http://www.planalto.gov.br. Acceso en 09 mar. 2017.

OCB. Ramo Habitacional. Recuperado de: http://www.ocb.org.br/ramo-habitacional. Acceso en 30 abr. 2018.

Superior Tribunal de Justiça. Recurso Especial n. 1.535.888/MG. Relatora Ministra Nancy Andrighi. Publicado en el DJe en 26/05/2017. Recuperado de: http://www.stj.jus.br. Acceso en: 29 jun. 2017. 
Superior Tribunal de Justiça. Regimento Interno do Superior Tribunal de Justiça. Brasília: STJ, 2018. Recuperado de: http://www.stj.jus.br. Acceso en: 13 out. 2017.

Superior Tribunal de Justiça. O que é?. Recuperado de: http://www.stj.jus.br. Acceso en: 13 out. 2019.

Superior Tribunal de Justiça. Súmula 602. Recuperado de: http://www.stj.jus.br. Acceso en: 27 abr. 2018.

Tribunal de Justiça do Distrito Federal e dos Territórios. Apelação Cível n. 2016.01.1.060385-6. Relator Desembargador Carlos Rodrigues. Recuperado de: http://www.tjdft.jus.br. Acceso en: 30 abr. 2018. 